\title{
Disseminated cryptococcosis with skin lesions: report of a case series*
}

\author{
Marina Zoéga Hayashida ${ }^{1}$ \\ Victor Pavan Pasin ${ }^{1}$ \\ Adriana Maria Porro ${ }^{1}$
}

\author{
Camila Arai Seque ${ }^{1}$ \\ Milvia Maria Simões e Silva Enokihara ${ }^{1}$
}

DOI: http:/ /dx.doi.org/10.1590/abd1806-4841.20176343

\begin{abstract}
Cryptococcosis is a common fungal infection in immunocompromised patients, caused by genus Cryptococcus, presenting with meningitis, pneumonia, and skin lesions. Cutaneous presentation can be varied, but specifically in solid organ transplant recipients (iatrogenically immunocompromised), cryptococcosis should always be considered in the differential diagnosis of cellulitis-like lesions, since the delay in diagnosis leads to worse prognosis and fatal outcome. We report four cases of cryptococcosis with cutaneous manifestation not only for its rarity, but also to emphasize the important role of the dermatologist in the diagnosis of this disease.
\end{abstract}

Keywords: Cryptococcosis; Cryptococcus neoformans; Immunosuppression; Skin manifestations; Kidney transplantation

\section{INTRODUCTION}

Cryptococcosis is an infection caused by opportunistic and encapsulated fungi of the genus Cryptococcus. ${ }^{1}$ Cryptococcus gattii species is most commonly responsible for cryptococcosis in immunocompetent individuals, while Cryptococcus neoformans is more common in immunocompromised patients. However, both can be found in any patient, and cause meningitis, pneumonia and cutaneous lesions. ${ }^{2-4}$

Cryptococcosis can present with skin lesions that are secondary to systemic hematogenous spread or primary, being the latter rarer. ${ }^{3,5}$ The clinical presentation of cutaneous lesions can be varied, therefore there are no typical lesions of this infection. ${ }^{3}$ In the immunocompromised patients, cryptococcosis must always be considered in the differential diagnosis of cellulitis-like or molluscum contagiosum-like lesions, because the delay in diagnosis can lead to a worse prognosis. ${ }^{6}$
We report four cases of systemic cryptococcosis with varied cutaneous presentations, including a bacterial cellulitis-like lesion, in renal transplant patients, showing the many forms of this infrequent infection in the skin and the importance of the dermatologist for their identification. This infection can progress to death if not treated early.

\section{CASE REPORT}

Cutaneous cryptococcosis was diagnosed in four male patients seen during dermatological interconsultations of a tertiary hospital, with a mean age of 41 years. Three were renal transplant patients, one of whom also had AIDS; the fourth patient had no diagnosed comorbidities (Table 1). All progressed during admission with skin lesions, that were the reason for dermatology interconsultation. In three of them, the lesions themselves were the reason for hospital admission.

\footnotetext{
Study submitted in 04.08.2016

Approved by the Advisory Board and accepted for publication on 23.11.2016

* Study conducted at Escola Paulista de Medicina, of the Universidade Federal de São Paulo (EPM-UNIFESP) - São Paulo (SP), Brazil. Financial Support: None.

Conflict of Interests: None.

1 Department of Pathology, Escola Paulista de Medicina - Universidade Federal de São Paulo (EPM-UNIFESP) - São Paulo (SP), Brazil.

(일 by Anais Brasileiros de Dermatologia
} 
All renal transplant patients were under immunosuppressant treatment. Patient 1 was taking mycophenolate mofetil and prednisone; patient 3 mycophenolate sodium, tacrolimus and prednisone; and patient 4, azathioprine, tacrolimus and prednisone. Patient 1 was also on antiretroviral therapy for HIV with lamivudine, zidovudine and lopinavir/ritonavir (Table 1).

On dermatological examination, patient 1 had brown plaques covered with normochromic nodules with smooth surface on the anterior aspect of the legs; patient 2 had erythematous, firm nodules with crusts and hemorrhagic dots on the left eyebrow and forearm; patient 3 had a red-brown plaque with mild scaling on the left leg; and patient 4 had five firm red-purple plaques on the medial aspect of the left knee, forearm and hip, and right leg and thigh (Figures 1 and 2).

A biopsy was taken from the lesions of the patients, and histopathology confirmed the diagnosis of cryptococcosis in all cases (Figure 3). Cultures of the biopsy specimens were positive for Cryptococcus in three cases and negative in one. All patients were diagnosed with disseminated cryptococcosis with extracutaneous involvement. All patients had central nervous system involvement, and patients 2 and 4 also had the lungs affected.

Treatment was started with amphotericin B and fluconazole for patients 1, 2 and 3 for two weeks, then maintenance therapy with fluconazole alone. Patient 4 received amphotericin B and flucytosine for two weeks, and maintenance therapy was made with fluconazole alone.

\section{DISCUSSION}

Cryptococcus infection usually occurs after inhalation of the fungus, with deposition of spores into the pulmonary alveoli. In immunocompetent individuals, the organism develops a polysaccharide capsule that interferes with phagocyte recognition and opsonization. In immunocompromised individuals, and those with cellular immunity deficiency in particular, there can be hematogenous dissemination particularly to the central nervous system, but also to kidneys, bones and skin. ${ }^{5}$ The systemic form is defined as the involvement of two or more non-adjacent areas. ${ }^{6}$

Skin and soft tissue involvement is relatively rare $(10 \%$ a $20 \%$ ) but is almost always considered a marker for disseminated disease, and can sometimes precede the diagnosis of systemic infection. ${ }^{78}$ Cutaneous clinical presentation is varied; there can be papules, pustules, nodules, abscesses, edema, panniculitis, ulcers and cellulitis-like and molluscum contagiosum-like lesions. ${ }^{4,8}$ In immunosuppressed patients, such as solid organ transplant patients, the cutaneous presentation can simulate other conditions such as bacterial cellulitis or panniculitis, clinically indistinguishable, in many

TABLE 1: Clinical data and laboratory tests results of four patients with disseminated cryptococcosis

\begin{tabular}{|c|c|c|c|c|c|c|}
\hline Patient & $\begin{array}{l}\text { Age } \\
\text { (years) }\end{array}$ & Comorbidity & Medication & Pathology & $\begin{array}{l}\text { Culture from } \\
\text { skin specimen }\end{array}$ & Treatment \\
\hline 1 & 25 & $\begin{array}{l}\text { RTR } 1 \text { year and } 3 \text { months } \\
\text { back (kidney loss of un- } \\
\text { known cause); AIDS for } \\
6 \text { years (CD4 } 85 \text { cells/ } \\
\text { mm3) }\end{array}$ & $\begin{array}{l}\text { MMF and pred- } \\
\text { nisone; lamivu- } \\
\text { dine, zidovudine } \\
\text { and lopinavir/ } \\
\text { ritonavir }\end{array}$ & $\begin{array}{l}\text { Cryptococco- } \\
\text { sis }\end{array}$ & $\begin{array}{l}\text { Cryptococcus } \\
\text { neoformans }\end{array}$ & $\begin{array}{l}\text { Amphotericin B } \\
\text { and fluconazole }\end{array}$ \\
\hline 2 & 38 & No comorbidities & - & $\begin{array}{l}\text { Cryptococco- } \\
\text { sis }\end{array}$ & $\begin{array}{l}\text { Cryptococcus } \\
\text { neoformans }\end{array}$ & $\begin{array}{l}\text { Amphotericin B } \\
\text { and fluconazole }\end{array}$ \\
\hline 3 & 47 & $\begin{array}{l}\text { RTR } 3 \text { years and } 8 \\
\text { months back (kidney } \\
\text { loss secondary to HTN) }\end{array}$ & $\begin{array}{l}\text { MFNa, tacrolimus } \\
\text { and prednisone }\end{array}$ & $\begin{array}{l}\text { Cryptococco- } \\
\text { sis }\end{array}$ & $\begin{array}{l}\text { Cryptococcus } \\
\text { spp. }\end{array}$ & $\begin{array}{l}\text { Amphotericin B } \\
\text { and fluconazole }\end{array}$ \\
\hline 4 & 56 & $\begin{array}{l}\text { RTR } 7 \text { months back (kid- } \\
\text { ney loss secondary to } \\
\text { HTN) }\end{array}$ & $\begin{array}{l}\text { Azathioprine, tac- } \\
\text { rolimus and pred- } \\
\text { nisone }\end{array}$ & $\begin{array}{l}\text { Cryptococco- } \\
\text { sis }\end{array}$ & Negative & $\begin{array}{l}\text { Amphotericin B } \\
\text { and flucytosine; } \\
\text { then, flucona- } \\
\text { zole }\end{array}$ \\
\hline
\end{tabular}

RTR: renal transplant recipient/AIDS: acquired immunodeficiency syndrome/HTN: systemic hypertension /MMF: mycophenolate mofetil/MFNa: mycophenolate sodium 

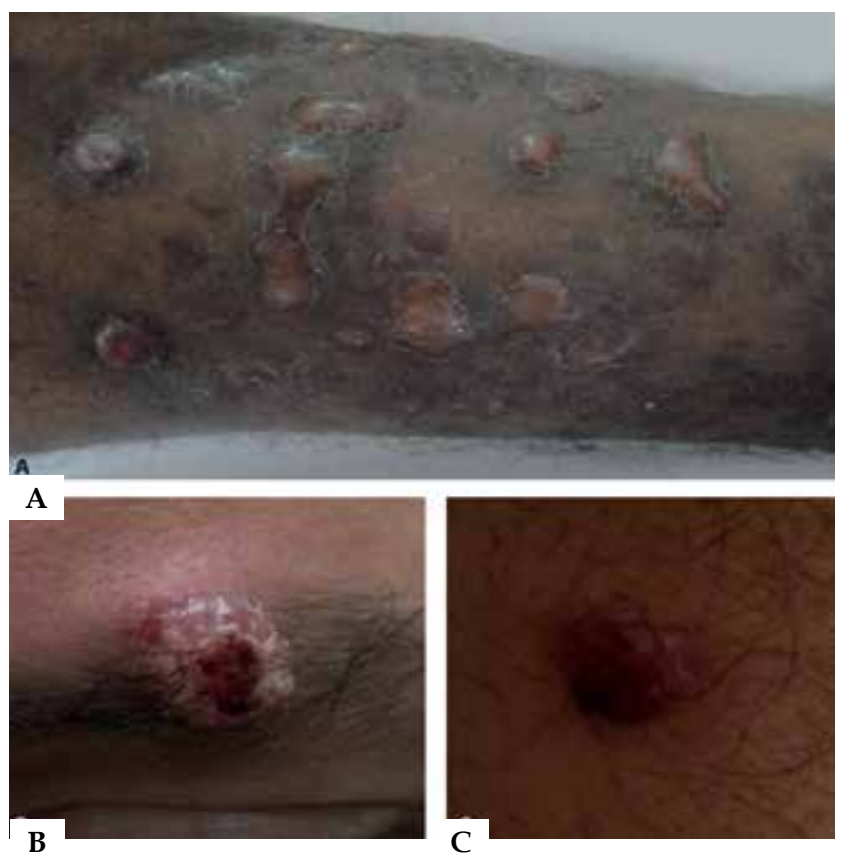

Figure 1: A: Brown plaques on the anterior aspect of the legs, with overlying normochromic, smooth surfaced nodules; B and C: erythematous firm nodules on the eyebrow (B) and forearm (C) with crusts and hemorrhagic dots
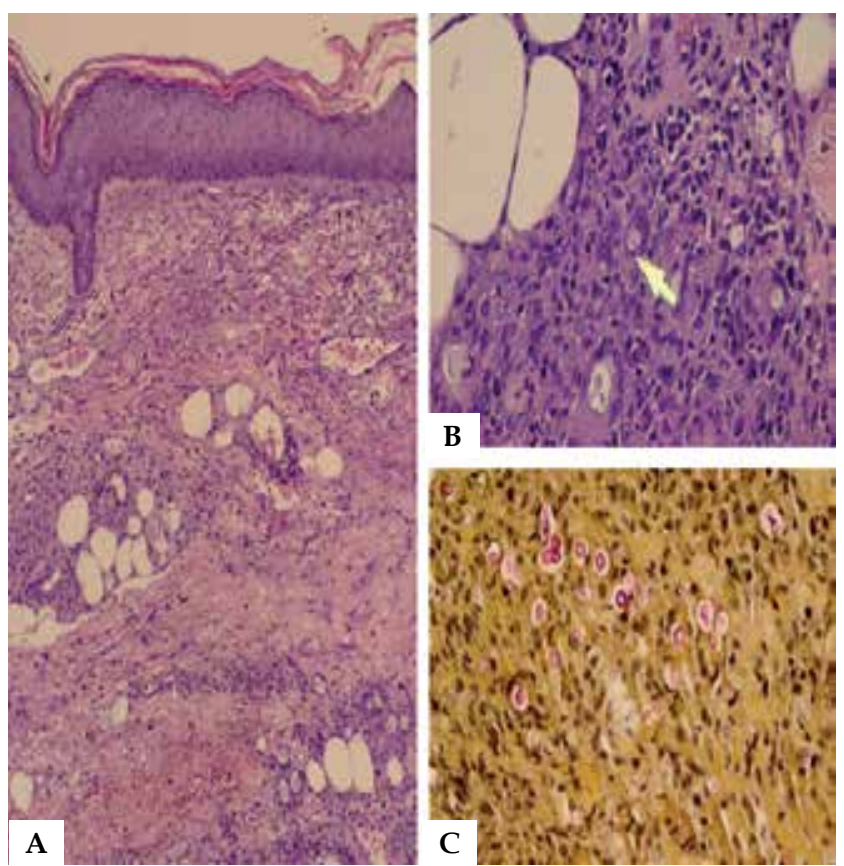

Figure 3: A: Skin biopsy from the forearm with a granulomatous inflammatory infiltrate in the dermis, with neutrophils and a large amount of fungi (Hematoxylin \& eosin, X40); B: In detail, the granuloma with suppuration and fungi with refringent capsule (Hematoxylin \& eosin, X400); C: Fungi capsules were stained red by the special staining Mayer's mucicarmine (X400).

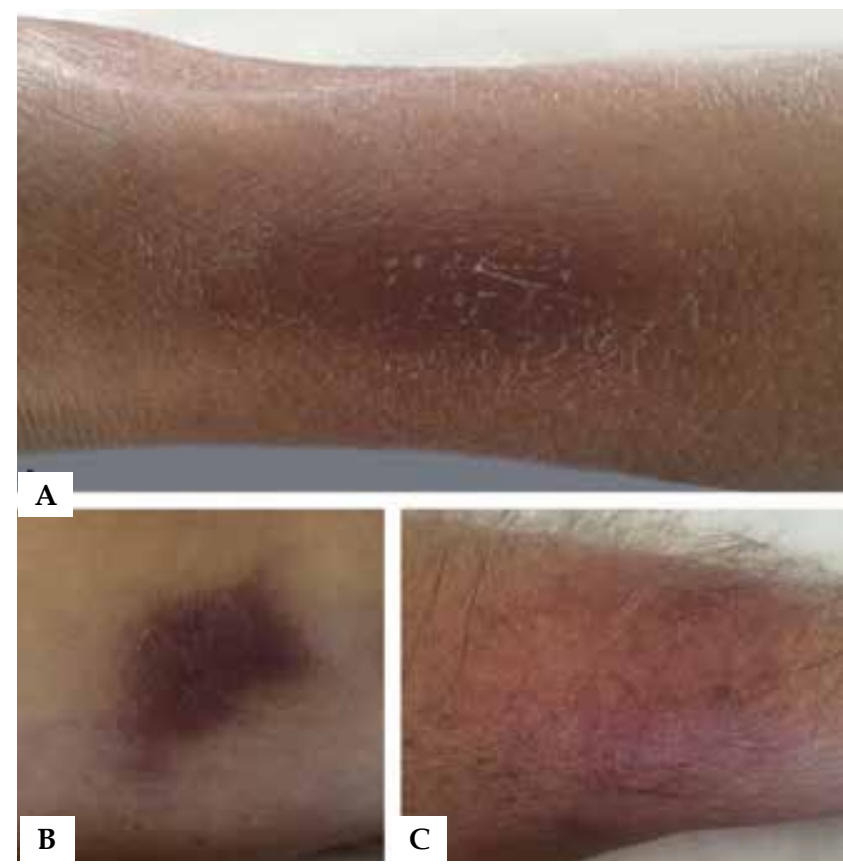

FIGURE 2: A: Erythematous plaque on the left leg, with mild scaling; B and C: red-purple plaque, hardened on palpation, on the medial aspect of the knee (B) and forearm (C)

cases leading to delay in diagnosis and appropriate treatment. ${ }^{1,6-9}$

Diagnosis can be made by microscopy, culture of secretions, histopathology, serology or PCR., ${ }^{3,7}$ The recommended treatment for disseminated infection must include three phases: 1) induction, with amphotericin B (liposomal, if available) associated with 5-flucytosine for two weeks; 2) consolidation, with high doses of fluconazole $(400 \mathrm{mg} /$ day to $800 \mathrm{mg} /$ day) for eight to 10 weeks; and 3) maintenance, with fluconazole $\left(200 \mathrm{mg} /\right.$ day) for six to 12 months. ${ }^{10}$

We present a series of cases of cryptococcosis with cutaneous manifestation because of its rarity - since only a small percentage of patients will develop it - , and the importance of differentiation with other more common cutaneous infections, such as bacterial cellulitis and molluscum contagiosum. It is a severe systemic infection, that can progress in an unfavorable way when the diagnosis is delayed. We highlight the important role of the dermatologist in these cases.] 


\section{REFERENCES}

1. Probst C, Pongratz G, Capellino S, Szeimies RM, Schölmerich J, Fleck M, et al. Cryptococcosis mimicking cutaneous cellulitis in a patient suffering from rheumatoid arthritis:a case report. BMC Infect Dis. 2010;10:239.

2. Chen S, Sorrell T, Nimmo G, Speed B, Currie B, Ellis D, et al. Epidemiology and host- and variety-dependent characteristics of infection due to Cryptococcus neoformans in Australia and New Zealand. Australasian Cryptococcal Study Group. Clin Infect Dis. 2000;31:499-508.

3. Du L, Yang Y, Gu J, Chen J, Liao W, Zhu Y. Systemic Review of Published Reports on Primary Cutaneous Cryptococcosis in Immunocompetent Patients. Mycopathologia. 2015;180:19-25.

4. Kikuchi N, Hiraiwa T, Ishikawa M, Mori T, Igari S, Hanami Y, et al. Cutaneous Cryptococcosis Mimicking Pyoderma Gangrenosum: A Report of Four Cases. Acta Derm Venereol. 2016;96:116-7.

5. McKinney JL, Cerio D, Loghmanee C, Pinho P, Gomes R, Patel M, et al. Surgical Management of Primary Cutaneous Cryptococcosis after Failed Medical Management. J Hand Microsurg. 2015;7:116-8.

6. Valente ES, Lazzarin MC, Koech BL, da Rosa RV, de Almeida R, de Oliveira UL, et al. Disseminated cryptococcosis presenting as cutaneous cellulitis in an adolescent with systemic lupus erythematosus. Infect Dis Rep. 2015;7:5743.

7. Lazzara M, Joshi A. Disseminated cryptococcosis involving the head and neck. BMJ Case Rep. 2014;2014.

8. Reddy BY, Shaigany S, Schulman L, Grossman ME. Case Report: Fatal Cryptococcal Panniculitis in a Lung Transplant Recipient. J Drugs Dermatol. 2015;14:519-22.

9. Ni W, Huang Q, Cui J. Disseminated cryptococcosis initially presenting as cellulitis in a patient suffering from nephrotic syndrome. BMC Nephrol. 2013;14:20.

10. Perfect JR, Dismukes WE, Dromer F, Goldman DL, Graybill JR, Hamill RJ et al. Clinical practice guidelines for the management of cryptococcal disease: 2010 update by the infectious diseases society of america. Clin Infect Dis. 2010;50:291-322.

\author{
MAILING ADDRESS: \\ Marina Zoéga Hayashida \\ Rua Borges Lagoa, 508 \\ Vila Clementino \\ São Paulo, SP \\ Brazil \\ E-mail:mahayashida@hotmail.com
}

How to cite this article: Hayashida MZ, Seque CA, Pasin VP, Enokihara MMSS, Porro AM. Disseminated cryptococcosis with skin lesions: report of a case series. An Bras Dermatol. 2017;92(5 Suppl 1): 69-72. 